\title{
Review Article \\ Prenatal Exposures to Multiple Thyroid Hormone Disruptors: Effects on Glucose and Lipid Metabolism
}

\author{
Deborah Molehin, ${ }^{1}$ Marloes Dekker Nitert, ${ }^{1,2}$ and Kerry Richard ${ }^{1,2,3,4}$ \\ ${ }^{1}$ School of Medicine, The University of Queensland, Herston, QLD 4029, Australia \\ ${ }^{2}$ UQ Centre for Clinical Research, The University of Queensland, Herston, QLD 4029, Australia \\ ${ }^{3}$ Conjoint Endocrine Laboratory, Chemical Pathology, Pathology Queensland, Queensland Health, Herston, QLD 4029, Australia \\ ${ }^{4}$ School of Biomedical Sciences, Queensland University of Technology, Brisbane, QLD 4001, Australia
}

Correspondence should be addressed to Kerry Richard; kerry.richard@qimrberghofer.edu.au

Received 27 October 2015; Revised 8 January 2016; Accepted 12 January 2016

Academic Editor: Noriyuki Koibuchi

Copyright (C) 2016 Deborah Molehin et al. This is an open access article distributed under the Creative Commons Attribution License, which permits unrestricted use, distribution, and reproduction in any medium, provided the original work is properly cited.

Background. Thyroid hormones (THs) are essential for normal human fetal development and play a major role in the regulation of glucose and lipid metabolism. Delivery of TH to target tissues is dependent on processes including TH synthesis, transport, and metabolism. Thyroid hormone endocrine disruptors (TH-EDCs) are chemical substances that interfere with these processes, potentially leading to adverse pregnancy outcomes. Objectives. This review focuses on the effects of prenatal exposures to combinations of TH-EDCs on fetal and neonatal glucose and lipid metabolism and also discusses the various mechanisms by which TH-EDCs interfere with other hormonal pathways. Methods. We conducted a comprehensive narrative review on the effects of TH-EDCs with particular emphasis on exposure during pregnancy. Discussion. TH imbalance has been linked to many metabolic processes and the effects of $\mathrm{TH}$ imbalance are particularly pronounced in early fetal development due to fetal dependence on maternal TH for proper growth and development. The pervasive presence of EDCs in the environment results in ubiquitous exposure to either single or mixtures of EDCs with deleterious effects on metabolism. Conclusions. Further evaluation of combined effects of TH-EDCs on fetal metabolic endpoints could improve advice provided to expectant mothers.

\section{Introduction}

Pregnancy results in many physiological changes that have significant effects on thyroid status [1]. The fetus relies exclusively on maternal thyroid hormone $(\mathrm{TH})$ in early pregnancy for growth, neurodevelopment, and the regulation of metabolic processes [2,3]. Dysregulation in glucose and lipid metabolism has been associated with many metabolic syndromes including gestational diabetes mellitus (GDM) and TH imbalance is a contributing factor to these diseases $[4,5]$. The global prevalence of GDM and obesity is rising in the obstetric population and their effects on maternal and fetal outcomes are well documented [6-8].

Caloric intake and personal lifestyle are strongly associated with obesity and metabolic syndrome; however, there is a growing concern that a subgroup of endocrine disrupting chemicals (EDCs) known to specifically alter TH regulation
(TH-EDCs) may contribute to the prevalence of metabolic syndromes by altering signalling pathways involved in glucose and lipid homeostasis during pregnancy. The risk of exposure to TH-EDCs is rising with exposure to multiple TH-EDCs more common than exposure to single chemicals. Several studies have reported the effects of exposure to individual EDCs and this has been reviewed elsewhere [9]. This review discusses the effects of combinations of $\mathrm{TH}$ endocrine disruptors on the regulation of glucose and lipid metabolism during pregnancy.

\section{Method}

For this narrative review conducted between 2014 and 2015, the PubMed (US National Library of Medicine, National Institutes of Health) and Google Scholar databases were 
interrogated with the following key words and phrases: $\mathrm{TH}$ endocrine disruptors and pregnancy/early or late pregnancy; prenatal effect of TH endocrine disruptors on glucose/lipid metabolism; mechanism of action of TH endocrine disruptors; placental transfer/biotransformation of $\mathrm{TH}$ endocrine disruptors. All study types including randomized controlled trials, case-control, human, and animal studies were considered and results are restricted to English only. The articles were grouped according to the effects of the TH-EDCs on related endpoints.

\section{Results and Discussion}

3.1. Thyroid Hormone Synthesis, Secretion, and Metabolism. The THs thyroxine (T4) and triiodothyronine (T3) are synthesized and secreted by the thyroid gland. Thyroid epithelial cells synthesize thyroglobulin, which provides tyrosine residues that are iodinated to iodotyrosine by thyroid peroxidase (TPO) to form T4 and T3 (20\% of total T3 is made by the thyroid gland) [10]. Maintenance of blood $\mathrm{TH}$ levels occurs through a hypothalamic-pituitary-thyroid axis feedback mechanism [10]. Basically, TSH-releasing hormone (TRH) in the hypothalamus stimulates thyroid stimulating hormone (TSH) secretion from the anterior pituitary, which in turn initiates TH synthesis and release from the thyroid gland. TH also acts at the transcriptional level to suppress the synthesis of TRH and TSH (Figure 1).

THs are highly lipophilic and are secreted into the blood stream where they are bound by the $\mathrm{TH}$ distribution proteins thyroxine binding globulin (TBG), transthyretin (TTR), or albumin [11]. TH cellular uptake is regulated by cell specific expression of $\mathrm{TH}$ transporters including organic aniontransporting polypeptides (OATPs), large neutral amino acid transporters (LATs), and monocarboxylate transporters 8 and 10 (MCT8, MCT10) (Figure 2).

Once inside the cell, the deiodinase enzymes (Type 1(D1), Type 2 (D2), and Type 3 (D3)) regulate the conversion of T4 to either active T3 (D1 and D2) or inactive reverse T3 (rT3) (D1 and D3) by the removal of a specific iodine atom [12]. Metabolizing enzymes such as uridine $5^{\prime}$-diphosphoglucuronosyltransferases (UDP-GT) and sulfotransferases also regulate $\mathrm{TH}$ bioavailability by rendering $\mathrm{THs}$ more water soluble and more easily excreted [13].

THs converted to $\mathrm{T} 3$ in the cell can either activate or repress gene transcription by binding to nuclear $\mathrm{TH}$ receptors (TRs) which are DNA-binding transcription factors that bind specific thyroid hormone response elements (TREs) in the regulatory region of target genes [14]. TRs may bind TREs as homodimers but also commonly bind as heterodimers with other nuclear receptors such as the retinoid X receptor (RXR) [15].

A person is described as euthyroid when the thyroid gland is functioning normally resulting in normal steady state levels of serum THs and TSH. Hypothyroidism results when the thyroid gland does not produce adequate amounts of $\mathrm{TH}$ resulting in low serum $\mathrm{TH}$ levels and elevated $\mathrm{TSH}$. Hyperthyroidism results from the thyroid gland producing too much $\mathrm{TH}$ resulting in high $\mathrm{TH}$ and suppressed TSH in the serum. Both hypo- and hyperthyroidism commonly result from autoimmune disease attack of TPO (hypo- and hyper-), thyroglobulin (hypo-), TSH receptor antibodies, and thyroid stimulating immunoglobulin (hyper-). When serum $\mathrm{TH}$ levels fall within the normal range but TSH levels are not normal (autoantibodies are also often present), this signifies the early stages of thyroid disease and is described as a subclinical state [38]. TH disrupting chemicals would clearly have different effects on individuals with different types of thyroid disorder.

3.2. Thyroid Hormone Metabolism and Pregnancy. TH levels are markedly altered by the hormonal and metabolic demands of normal pregnancy [39]. The placenta secretes a glycoprotein hormone called human chorionic gonadotropin (hCG), which possesses structural similarities to TSH and acts as a weak TSH receptor agonist [40]. Due to elevated levels of estrogen and hCG in pregnancy, a marginal increase in the basal TSH and serum TBG as well as alterations in TH levels and peripheral metabolism of maternal TH is believed to alter the thyroid hormone system [41].

The maternal thyroid gland accommodates the demands of pregnancy and a growing fetus by increasing hormonal output. The human fetal thyroid can secrete $\mathrm{TH}$ from 16 weeks of gestation [42], whereas prior to this the fetus is dependent on transplacental supply of maternal T4. In the first trimester, there is a parallel increase in total T4 concentration in the maternal and fetal compartments. Lower T3 but higher rT3 concentrations were observed in coelomic and amniotic fluids [43]. This was attributed to high fetal D3 and sulfotransferase activities and confirmed by reports of high D3 activities in fetal hepatic and placental tissues $[44,45]$. In addition, due to lower levels of binding proteins such as TTR in the human fetus, a higher proportion of maternally transferred T4 exists as free T4 in the coelomic fluid cavities [43]. TTR is produced and secreted by the human placenta [46] and binds T4 with high affinity and may transport maternal $\mathrm{T} 4$ to the fetus.

\subsubsection{Effects of Thyroid Hormones on Glucose Metabolism.} Glucose metabolism is altered during pregnancy to guarantee adequate delivery of nutrients to the growing placenta and fetus. In pregnancy, maternofetal glucose transport is largely dependent on the expression of one or more member of the facilitative family of glucose transporters (GLUTs) in the placenta. Increased fat mass in overweight and obesity is associated with prepregnancy insulin resistance, which is compounded by insulin resistance of pregnancy $[47,48]$. In late pregnancy, insulin resistance is associated with hepatic gluconeogenesis and decreased utilization of glucose by peripheral tissues which contribute to meeting the increasing placental and fetal energy demands $[49,50]$. With higher prepregnancy insulin resistance, for example, in obesity, the additional pregnancy-induced insulin resistance cannot always be compensated for by increased insulin secretion resulting in overt hyperglycemia. Gestational diabetes mellitus (GDM) is hyperglycemia first detected during pregnancy and may affect up to $17.8 \%$ of pregnancies [51]. The etiology 


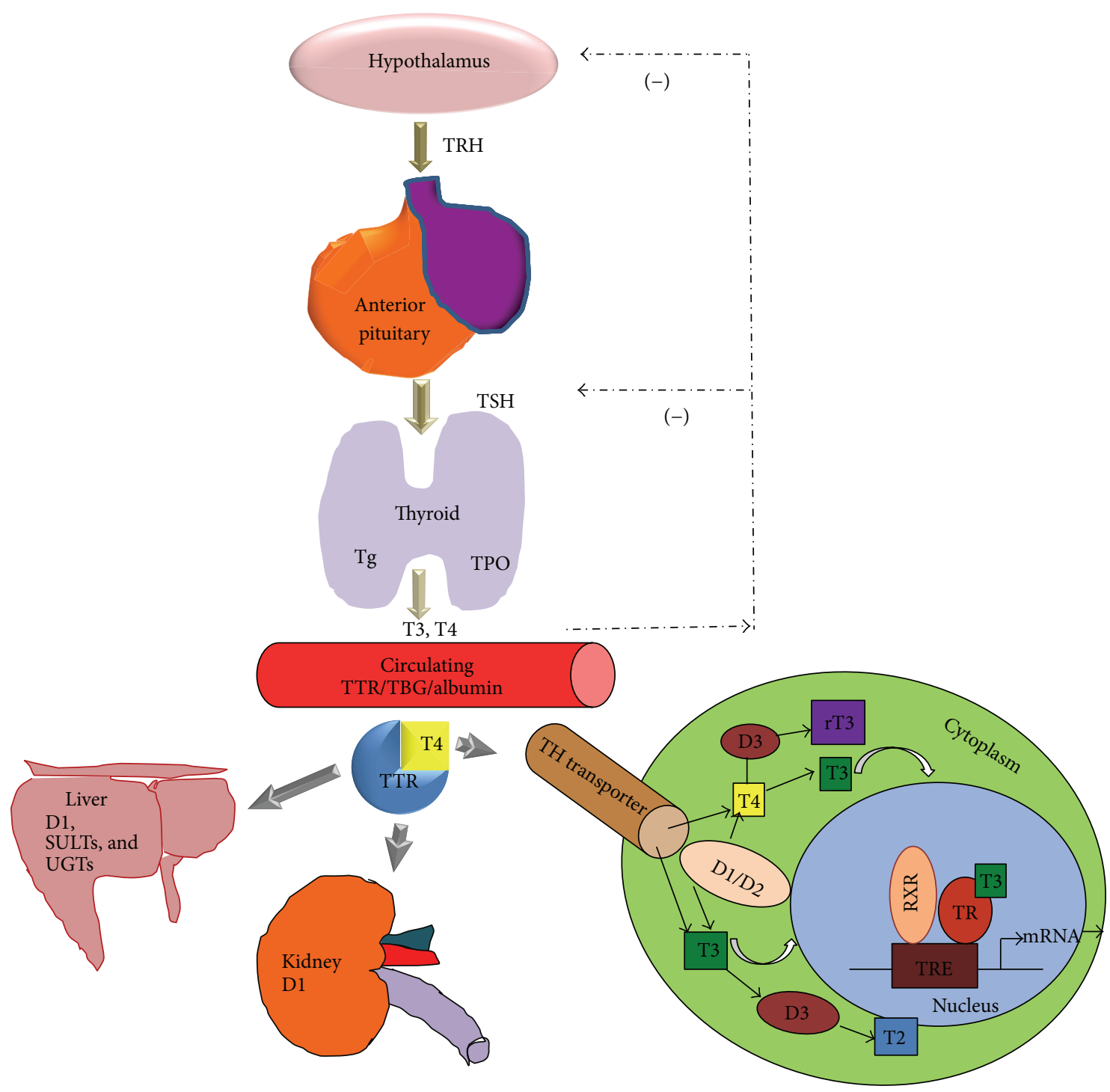

FIgURE 1: Thyroid hormone synthesis and secretion regulated through a negative feedback loop. In the hypothalamus, Thyrotropin- (TSH-) releasing hormone (TRH) stimulates the anterior pituitary gland to secrete thyroid stimulating hormone (TSH) which then initiates thyroid hormone (TH) synthesis and release from the thyroid gland by the action of thyroid peroxidase enzyme (TPO) on thyroglobulin (Tg). TRH and TSH are inhibited by negative (-) feedback of the thyroid hormones. Thyroxine (T4) and triiodothyronine (T3) are released into the circulation where they bind thyroid hormone binding proteins, namely, transthyretin (TTR), thyroxine binding globulin (TBG), and albumin. These complexes are then transported into cells via TH transporters. In the cell, Types 1 and 2 deiodinase enzymes convert T4 to T3, which then enters the nucleus and binds with thyroid hormone receptors (TRs) which in turn bind other nuclear receptors (e.g., retinoid X receptor (RXR)). These receptor complexes then bind thyroid hormone responsive elements (TREs) on target genes which results in the transcription of the DNA sequence to messenger ribonucleic acid (mRNA). Deiodinase Type 3 (D3) also regulates thyroid hormones by converting T4 and T3 to reverse T3 (rT3) and 3,5-diiodo-L-thyronine (T2), respectively. In the liver, deiodinase Type 1 (D1) enzyme is involved in both T3 production and clearance of plasma rT3. Thyroid hormone is also metabolized by conjugation to sulphate (by sulfotransferases (SULTs)) and glucuronic acid (by UDP-glucuronosyltransferase (UGTs)). Conjugation increases the water solubility of TH, facilitating its rapid degradation. In the kidney, Type 1 (D1) deiodinase is also involved in T3 production and excretion of thyroid hormones.

of GDM has been attributed to genetic predisposition, insulin resistance, and altered beta cell function [52-54].

$\mathrm{TH}$ affects many aspects of glucose metabolism: circulating insulin levels and counter-regulatory hormones; hepatic gluconeogenesis and glycogenolysis; and intestinal glucose uptake. TH regulates the transcription of several genes involved in glucose metabolism. At the tissue level,
TH actions on glucose metabolism are regulated by transmembrane transporters, ligand-dependent $\mathrm{TH}$ receptors, and deiodinases [55].

Deranged TH levels in pregnancy are associated with adverse maternal and fetal metabolic outcomes [4, 56, 57]. Excess TH increases basal metabolic rate with a concomitant increase in the demand for glucose [58]. In response to excess 


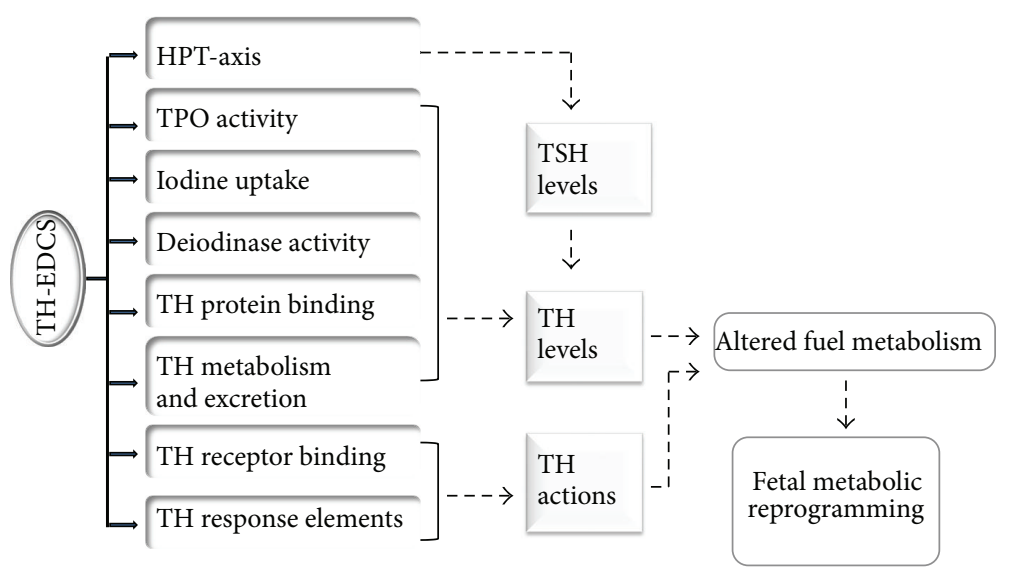

FIGURE 2: TH-EDCS targets and effect on fetal fuel metabolism. Thyroid hormone endocrine disrupting chemicals (TH-EDCs) disrupt the thyroid economy by altering the hypothalamus, anterior pituitary, and thyroid axis (HPT-axis) which results in altered thyroid stimulating hormone (TSH) levels and in turn the thyroid hormone (TH) levels. TH-EDCs also interfere with the synthesis of TH by inhibiting thyroid peroxidase (TPO) activity, iodine uptake, and deiodinase activity, TH binding to transport proteins, and TH metabolism and excretion which all result in the alteration of TH levels. TH-EDCs inhibit TH binding at the TH receptors and at the TH response elements (TREs); this results in the inhibition of TH action on target genes. Alterations in the TH levels as well as its action lead to altered fuel metabolism and eventually in fetal metabolic reprogramming.

$\mathrm{TH}$, pancreatic $\beta$ cells continuously secrete insulin even in the absence of stimulatory glucose concentrations. This results in hyperinsulinemia and subsequently insulin resistance [59]. Untreated hyperthyroidism, although uncommon in pregnant women, may lead to restricted fetal growth, stillbirth, or preterm delivery due to reduced availability of nutrients to the fetus $[60,61]$. Furthermore, in healthy pregnant women with normal prepregnancy thyroid function, lower free T4 concentrations and a higher conversion of free $\mathrm{T} 4$ to free $\mathrm{T} 3$ are positively correlated with elevated glucose levels after oral glucose load as well as higher fasting insulin when adjusted for BMI [56]. This suggests that variations in TH levels within euthyroid concentrations also impact glucose metabolism in pregnancy.

In contrast, evidence of decreased glucose production and utilization has been observed in overt and subclinical hypothyroidism [62]. TH replacement therapy in patients with subclinical hypothyroidism resulted in a partial reversal to the euthyroid state with significant reductions in glucosestimulated-insulin secretion (GSIS) [62]. This implies that poorly managed hypothyroidism could result in high nutrient availability for the fetus, leading to large gestational age infants predisposed to obesity later in life. Animal studies of maternal hypothyroidism have reported impaired brain development perhaps due to altered expression of GLUT protein isoforms in the placenta and fetal brain [63].

\subsubsection{Effects of Thyroid Hormones on Lipid Metabolism.} Maternal serum lipid concentrations increase as pregnancy progresses [64]. The dynamics of lipid metabolism during pregnancy vary with gestational age: accumulation of fat in early pregnancy (anabolic phase), shift to increased insulin resistance, decreased adipose tissue lipoprotein lipase (LPL) activity, and increased lipolysis in late pregnancy (catabolic phase) [65]. The rise in maternal insulin resistance allows more glucose to be transported to the fetus in late pregnancy while the mother utilizes lipids as her main energy source. The placental transport of fatty acids to the growing fetus is mediated by lipoprotein receptors, lipid carrier proteins, and actions of lipase enzymes [65]. The exact mechanisms of placental lipid transport are however still unclear.

Maternal lipid metabolism in normal and complicated pregnancies has recently been reviewed [66]. In women with GDM, the higher levels of insulin resistance are associated with increased adipose tissue lipolysis and higher free fatty acids and triglycerides in maternal serum, increasing fetal nutrient availability resulting in fetal overgrowth [67].

$\mathrm{TH}$ is a main regulator of lipid metabolism. The expression of TH receptor isoforms is an important determinant of its actions on lipid metabolism [68]. The overall effects of $\mathrm{TH}$ on lipid metabolism are the sum of its actions primarily in the liver and adipose tissue. In the liver, TH stimulates lipogenesis, whereas in adipose tissue TH stimulates lipolysis [68]. TH increases hepatic cholesterol uptake and synthesis mainly not only by inducing the transcription of the LDLreceptor [69] but also by reducing apolipoproteins B48 and B100 [70], which is associated with increased hepatic triglyceride production. The higher TH levels in pregnancy may contribute to the increased lipid levels observed in the maternal circulation. Effects of TH and its receptors on rodent lipid metabolism have been reviewed [71].

Thyroid dysfunction has been associated with abnormal lipid profiles. During normal pregnancy, altered TH levels have been associated with a less favorable metabolic phenotype in pregnant women with normal thyroid function prepregnancy [56, 72]. Hyperthyroidism is characterised by an increased turnover of LDL cholesterol resulting in decreased plasma lipid levels [73]. In contrast, hypothyroidism in late pregnancy has been associated with enhanced cholesterol levels and decreased triglycerides and HDLcholesterol levels in rats [74]. Because of the importance of $\mathrm{TH}$ in regulating glucose and lipid metabolism in pregnancy 
TABLE 1: Hallmarks and effects of hyper-/hypothyroidism on fetal growth.

\begin{tabular}{lcc}
\hline & Hyperthyroidism & Hypothyroidism \\
\hline Metabolic rate & ++ & - \\
Glucose demand by tissues & ++ & - \\
Glucose stimulated insulin secretion & - & - \\
Hyperinsulinemia & ++ & N/A \\
Insulin resistance & ++ & N/A \\
Glucose disposal & - & - \\
Hepatic gluconeogenesis & ++ & ++ \\
Lipogenesis & + & ++ \\
Lipolysis & ++ & - \\
Fetal growth & - & ++ \\
\hline
\end{tabular}

++ symbolizes increase and - symbolizes a decrease, whereas N/A means not applicable.

and thereby the growth of the baby, substances that affect TH may have large effects on the health and development of mother and infant (Table 1).

\subsection{Thyroid Hormone Endocrine Disrupting Chemicals.} Exogenous substances capable of interfering with the structure or function of the endocrine system are known as endocrine disrupting chemicals (EDCs). As with other hormones, $\mathrm{TH}$ is a target of EDCs and many studies have identified chemicals that alter TH homeostasis. TH-EDCs may be clustered into two main groups based on their biodegradability and bioaccumulation in the environment. Nonpersistent organic chemicals (N-POCs) are widespread in the environment but are nonlipophilic and do not bioaccumulate. Persistent organic chemicals (POCs) are highly stable lipophilic compounds that bind to adipose tissue in living organisms and bioaccumulate up the food chain. NPOCs and some POCs are rapidly metabolized by enzymes and eliminated from the body. Organochlorine (OC) and organophosphate (OP) pesticides are highly lipophilic; OPs are unstable and therefore more readily metabolized than OCs which have been found to accumulate in adipose tissue [75].

TH-EDCs are ubiquitous and originate from chemical additives used as flame retardants; synthetic plasticizers and solvents used in food packaging, polyvinyl chloride tubing, medical equipments, pesticides, toys, personal products, adhesives, powder paints, and dental sealants; antimicrobial compounds used in household detergents; toxic byproducts of combustion processes; insulating materials for electrical equipment such as transformers and capacitors, heat transfer systems, hydraulic fluids, and lubricants; airbag inflation systems, fireworks, nitrate fertilizers, matches, and oxidants in propelling rockets and missiles; and synthetic and naturally predominant compounds in soy rich foods $[9,16,76]$. Humans come in contact with these chemicals through ingestion, inhalation, dermal exposure to contaminated substances, and intravenous and parenteral absorption from medical devices containing phthalates. species: altering deiodinase activity [25, 28, 77], inhibiting TH excretion or metabolism [26, 29], blocking iodine uptake by thyroid cells [33], competitively binding the thyroid transport protein TTR, the inhibition of human TPO $[36,37]$, and acting as an antagonist of complexes from the thyroid hormone responsive elements (TREs) [19, 78].

Certain TH-EDCs such as brominated flame retardants, hydroxylated polychlorinated biphenyls (PCBs) metabolites, and dioxin (PCDD) share structural similarities with TH and bind with the high affinity TH transport protein TTR [79], consequently inhibiting T4-TTR binding. In serum samples from polar bears, T4 binding sites on TTR displayed a higher affinity for halogenic phenols and PCBs. Supraphysiological levels of T4 were unable to displace these compounds when bound to TTR [80]. In pregnant rats, reduced fetal plasma and brain total T4 levels in response to prenatal exposure to hydroxylated PCBs were hypothesized to be due to the binding to TTR [77]. Many TH-EDCs not only affect $\mathrm{TH}$ but also interfere with the actions of other hormones acting through nuclear receptors such as sex hormones (estrogen, progesterone, and androgen) or by interacting with their respective nuclear receptors (ER, $\mathrm{PR}$, and $\mathrm{AR}$ ). In vitro toxicology studies of non-dioxinlike PCBs on humans revealed that PCB related compounds (congener) 168 and 125 completely inhibited T4-TTR binding because of their structural similarity to T4, but they also had very high androgen-inhibitory potencies. PCB-168 exhibited weak antiestrogenic activities whereas PCB-125 exhibited ERmediated activity. On the other hand, PCB-104 had high ARantagonistic potencies and was the most effective congener with estrogenic properties of all congeners studied [78]. Exposures to TH-EDCs in pregnancy have been associated with alterations in $\mathrm{TH}$ regulation and adverse pregnancy outcomes (Table 2).

The effects of TH-EDCs on the levels of TH or its receptor will affect downstream signalling including metabolic pathways. Bisphenol A functions as a selective TR-beta antagonist in vivo [81]. TR-beta is the main TR isoform in both liver and adipose tissue and BPA exposure could therefore reduce both lipogenesis and lipolysis reducing lipid availability in the circulation. Furthermore, the interactions between the TR and other nuclear receptors such as the RXR and FXR 


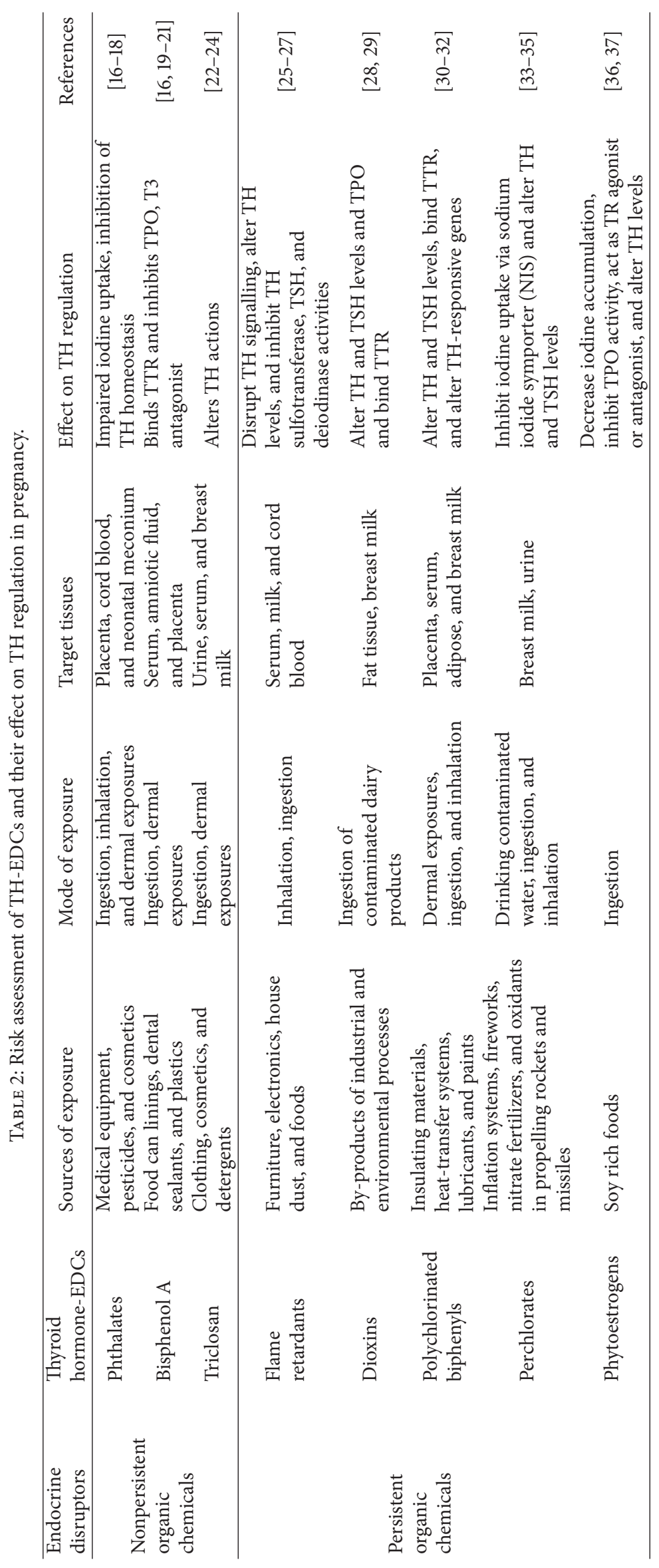


TABLE 3: TH signaling targets of different classes of TH-EDCs.

\begin{tabular}{|c|c|c|c|c|c|c|c|c|}
\hline TH-EDCs & $\begin{array}{l}\text { Iodine } \\
\text { uptake }\end{array}$ & $\begin{array}{c}\text { Inhibition } \\
\text { of TPO }\end{array}$ & $\begin{array}{l}\text { Binding to } \\
\text { TTR }\end{array}$ & TH levels & TSH levels & $\begin{array}{l}\text { Deiodinase } \\
\text { activity }\end{array}$ & Sulfotransferase activity & Transporter/receptor \\
\hline PBDE & & & & $\mathrm{x}$ & $\mathrm{x}$ & $\mathrm{x}$ & $\mathrm{x}$ & \\
\hline PCB & & & $\mathrm{x}$ & $\mathrm{x}$ & $\mathrm{x}$ & & & $\mathrm{x}$ \\
\hline TCDD & & & & & & & $\mathrm{x}$ & \\
\hline Triclosan & & & & & & & $\mathrm{x}$ & $\mathrm{x}$ \\
\hline Perchlorate & $\mathrm{x}$ & & & $\mathrm{x}$ & $\mathrm{x}$ & & & \\
\hline Flavonoids & $\mathrm{x}$ & $\mathrm{x}$ & & $\mathrm{x}$ & & & & $\mathrm{x}$ \\
\hline BPA & & $\mathrm{x}$ & $\mathrm{x}$ & $\mathrm{x}$ & & & $\mathrm{x}$ & \\
\hline Dioxin & & $\mathrm{x}$ & $\mathrm{x}$ & $\mathrm{x}$ & & & & $\mathrm{x}$ \\
\hline Phthalates & $\mathrm{x}$ & & & $\mathrm{x}$ & & & & \\
\hline
\end{tabular}

receptors further complicate the effects of EDCs since many TH-EDCs such as BPA independently affect other nuclear receptors which also affect lipid and glucose metabolism [82]. It may be possible to predict the effects of combinations of EDCs based on their individual TH signalling targets. A summary of TH signalling targets of different TH-EDCs is presented in Table 3.

3.3.2. Significance of the Effects of Multiple Endocrine Disruptor Exposures over Single Exposures. In modern society, most individuals will have been exposed to mixtures of EDCs rather than single EDC. Therefore, the study of the effects of combined chemicals is critical to reach meaningful conclusions on the plausible role of these chemicals on human health. Effects of EDCs can either be additive, synergistic, or antagonistic since chemicals may interact with one another to modify the nature of the toxic effect. For instance, human studies [83] revealed significant associations between increased levels of PCBs, dichlorodiphenyldichloroethylene (DDE), and hexachlorobenzene (HCB) with adverse thyroid volumes and multiple metabolic disorders, especially in older subjects. Complex mixtures may therefore result in more or additional deleterious effects on metabolism (Figure 2).

3.4. Prenatal Exposures to TH-EDCs. Prenatal exposure to EDCs continues to pose serious health risks to developing fetus and children as evidence of adverse effect on birth outcomes, childhood obesity, and intellectual disability are increasing $[4,84,85]$. More importantly, because organogenesis begins at the time when the fetus is solely dependent on maternal TH supply, early life exposure to TH-EDCs may lead to adverse short or long term health outcomes due to fetal reprogramming $[86,87]$.

3.4.1. Placental Transfer and Biotransformation of TH-EDCs. The placental barrier is not impervious to TH-EDCs as many of them have been measured in human fetal cord blood [88], neonatal meconium [89], rat fetal serum [22], and human amniotic fluid [17]. TH-EDCs are able to traverse the placental barrier by diffusion or via an active transporter (such as OATPs) either as pure or as biologically transformed chemicals (through conjugation of chemicals by placental metabolizing enzymes such as sulfotransferases (SULTs) and UDP-glucuronosyl transferases (UGTs)) (Figure 3). Biotransformation of chemicals by metabolizing enzymes makes the chemicals fit for excretion and may result in inactivation or increased toxicity. The biotransformed compounds can be extruded into the maternal circulation for excretion via placental transporters such as multidrug resistant-associated proteins. Expression of metabolizing enzymes and transporters has been shown to vary with gestational age in human [90] and animal placentas [91, 92]. The majority of the enzymes and transporters are expressed throughout human pregnancy with decreasing expression observed as pregnancy advances (e.g., UGT1 [93, 94]: P-glycoprotein (Pgp) [90]) whereas others are expressed during late pregnancy and continued during postnatal period [95]. The decline in the expression of transporters with gestational age is further corroborated by the increased rate of placental transfer and amount of P-gp substrates during late pregnancy compared to early pregnancy [96]. Some TH-EDC chemicals may alter other metabolic pathways thereby modulating the effect of metabolizing enzymes on endogenous substrates like steroid hormones [92] or other xenobiotics [97].

Ex vivo studies on human term placentas demonstrated that environmentally relevant levels of BPA in mothers freely diffuse across the placenta in an unconjugated form suggesting that SULTs and UGTs play a minor role in the transplacental transport of BPA. This was attributed to the low expression of placental enzymes involved in metabolizing the chemicals towards the end of pregnancy [98]. A similar study on term human placentas revealed that genistein, a naturally occurring phytoestrogen was able to traverse the placental barrier although only a small proportion was biotransformed by metabolizing enzymes in the placenta [99]. BPA and genistein both share similar metabolic pathways as well as estrogen disrupting effects [97]. UGT activity has been shown to be higher in human first trimester placenta compared to term placentas [94] and to decrease as pregnancy advances in humans [93]. This implies that the fetus is more protected from the toxic effect of TH-EDCs by UGT enzymes in early pregnancy than in late pregnancy, which might be a consequence of the vulnerable detoxification system in the infant in early pregnancy. This is different from animal models; here BPA actively traversed the rat term placenta 


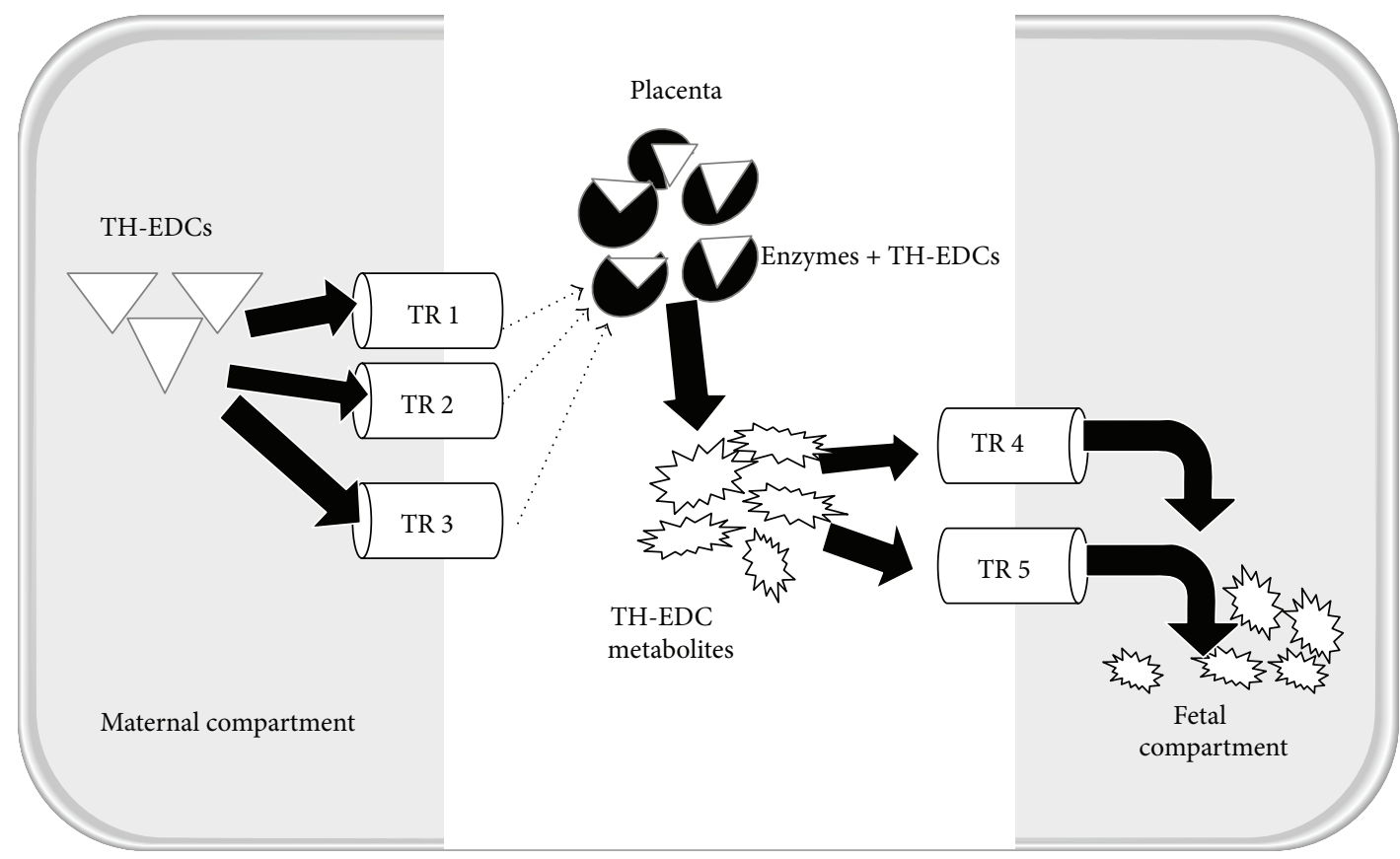

FIgURE 3: Placental transfer and biotransformation of TH-EDCs. Thyroid hormone endocrine disrupting chemicals (TH-EDCs) enter the placenta from the maternal compartment via various transporters located at the maternal interface of the placenta and are biotransformed by metabolizing enzymes to various metabolites that then enter the fetal compartment through transporters located at the fetal interface of the placenta. TR indicates transporters.

predominantly in its conjugated form and was deconjugated by $\beta$-glucuronidase enzymes in the rat fetus [100]. In addition to the low UGT activity observed in the rat fetus, high levels of Oatp4al and Mrpl transporters were expressed at the maternal and fetal interfaces of the placenta, respectively, suggesting that conjugated BPA is transferred from mothers by Oatp4al to the growing fetus by Mrp1 [100] leading to toxic effects of chemicals on the fetus.

3.4.2. Effects on Adipogenesis. Prenatal exposures to mixtures of TH-EDCs have revealed diverse ways by which chemicals alter TH homeostasis. Perinatal exposures to low doses of BPA increase abdominal adipocyte tissue mass and correlate with hyperlipidemia in a dose-response manner in mice [101]. However, exposures to low concentration of BPA had no adipogenic effect on murine mesenchymal stem cells in vitro [102]. Although the nonmonotonic effect of BPA, characterized by high responses at low and high exposure levels, is well known, it is worth mentioning that a much lower BPA concentration was administered to the pregnant mice than the mesenchymal stem cells. This discrepancy may be a result of the insulin resistant state in pregnancy, which is related to decreased adipogenesis. In normal pregnancy, placenta-derived hormones induce a state of insulin resistance with the aim of maintaining adequate energy supplies to the placenta and developing fetus. Insulin is known to promote lipogenesis in adipose tissue while suppressing lipolysis therefore an insulin resistant state will result in reduced lipogenesis while at the same time favoring lipolysis. A study of individual chemical effects on adipogenesis in animal models demonstrated an association between high doses of BPA and decreased adipocyte and lipid levels whereas diethylhexylphthalate (DEHP) and tributyltin (TBT) were linked to enhanced adipogenesis [102]. However, when studied together, the negative effect of BPA on adipogenesis was outweighed by the positive effect of DEHP and TBT on the proliferation of adipocytes at high concentrations with increased adipogenesis even though the effect was not as profound as observed with individual DEHP and TBT chemicals. No adipogenic effect was observed at low concentrations of the chemical mixture [103]. This suggests that the effect of chemical mixtures cannot be predicted from outcomes from individual chemicals due to varied mechanisms of action. In this case, BPA signals through the regulation of estrogen even though studies of BPA itself have shown that BPA can alter TH regulation [16]. On the other hand, DEHP and TBT both activate the peroxisome proliferator-activated receptors gamma $(\operatorname{PPAR} \gamma)$ signalling pathway.

3.4.3. Effects on Preterm Birth. Altered $\mathrm{TH}$ levels and postnatal thyroid function have been reported in preterm infants [104]. Epidemiological studies have revealed inverse or positive associations between maternal urinary BPA and mono-2-ethyl-5-hydroxyhexyl phthalate (MEHHP) with TH levels in adults and adolescents, respectively $[105,106]$. Also increases in BPA and MEHHP are associated with significant reductions in gestation in male offspring specific pregnancies in one [107] but not in another study [108]. These differences may be due to the small sampling population used in the study. 
3.4.4. Effects on Birth Weight. Higher maternal prepregnancy BMI and higher gestational weight gain are correlated with higher birth weight and fat mass at birth and increased BMI in young and adult offspring $[109,110]$. In addition, maternal preexisting diabetes and gestational diabetes have been associated with increased birth weight and development of later childhood obesity [111]. In a monotonic relationship, an increase in the dose of a chemical is attended by a corresponding increase in the effect of the chemical on the observed endpoint. Likewise, there is a corresponding decline in the effect with decreasing the doses of the chemicals. In male neonates, monotonic relationships were observed between phenols and birth weights; however, a Ushaped nonmonotonic association existed between phthalate metabolites and birth weights [112].

3.4.5. Long Term Effects on Obesity. Fetal exposures to phthalates and dichlorodiphenyldichloroethylene (DDE) have been associated with increased BMI and head circumference (HC) during the first year after birth in a nonmonotonic manner [88]. Animal studies revealed that exposures to a low dose of MEHP during pregnancy significantly increased body weight and fat pads of male offspring at 60 days after delivery, as well as serum cholesterol, triacylglycerol (TAG), and glucose levels in mice [113]. This demonstrates that lowdose effects cannot be predicted from outcomes at higher doses [114]. The specific effect on male offspring may be due to the interference of MEHP with male hormones as human epidemiological studies have revealed an association between MEHP and decreased steroid hormones in adult males [115]. Sex hormones have been linked to obesity [116] with positive relationship observed between androgen levels and BMI in females while a negative relationship exists between levels of androgen and small waist circumference in males [117]. In breast cancer cells, estrogen inhibits PPAR $\gamma$ [118], but MEHP is an agonist of PPAR $\gamma$ [119]. Hence, it can be speculated that, at low MEHP levels, the ratio of androgen to estrogen is high, therefore resulting in the observed obesity phenotype in male offspring. However, in female fetuses with higher estrogen to androgen levels, low level MEHP exposure would lead to estrogen inhibition of PPAR $\gamma$ activity and lipid metabolism.

Perinatal exposure to polychlorinated biphenyls (PCBs) and dioxins and their effects on puberty have been reviewed [120]. Exposure to PCB/dioxin has been linked to increased obesity, disruption of sex hormone signalling, retardation in the growth, and development of sex organs in males and breasts in girls. $\mathrm{PCB} /$ dioxin exert their role on puberty by interacting with the AhR which interferes with hormonal systems [120]. Prenatal exposure to a combination of PCBs and dichlorodiphenyldichloroethylene (DDE) may predispose female offspring to obesity in overweight mothers [121]. Exposure to DDE alone in infants of normal-weight women leads to more weight gain in the first 6 months postnatally and high BMI in early childhood [122]. Polychlorinated dibenzo-p-dioxins (PCDDs) and polychlorinated dibenzofurans (PCDFs) were found to significantly affect birth weight among male infants but not among female infants [123]. However, dietary dioxin and PCB intake was not associated with the risk for small-for-gestational age neonates [124]. This implies that some chemicals may have differential gender effects by interacting with some gender specific hormone receptors and signalling pathways such as estrogen and androgens.

3.4.6. Confounding Factors. Many studies have associated exposures of persistent organic pollutants with TH dysregulation $[27,28,30]$. The effects of some chemicals may be impacted by confounding factors such as maternal demographic and perinatal factors. Maternal gestational weight gain (GWG) has been implicated to influence the overall burden of persistent organic pollutants (POPs) in neonates [125]. In the anabolic phase of pregnancy, mothers use less of their stored fats, which would reduce the proportion of POPs that get liberated from fat stores. On the contrary, late pregnancy is marked by increased lipolysis, which may contribute to the increased release of compounds trapped in stored lipids, leading to an even higher exposure in the fetus. It could thus be that the level of exposure to POPs varies over the course of pregnancy.

A negative association was recorded between PBDE congeners and birth weight; however, when adjusted for maternal weight gain, these findings were no longer statistically significant. Also, no association was observed between PBDEs and birth length, head circumference, or gestational duration [126]. Exposure to PCBs and POPs during pregnancy has been linked to adverse effects on fetal growth [127129], increased birth weight [130], and shortened length of gestation in humans [131]. Prenatal exposures demonstrated a link between DDE and HCB with early postnatal growth but not with PCB [132]. It is crucial that confounders be identified in studies to rule out false positive results and to determine their role in maternal and fetal outcomes.

\section{Conclusions}

The role of TH-EDCs on metabolic risk factors such as insulin resistance, glucose tolerance, and triglycerides and cholesterol levels has only recently become the subject of research. Early studies suggest that TH-EDCs may act via a variety of mechanisms and that studies using high doses of these chemicals are probably not good predictors of effects at low doses. Additionally, low doses of combinations of chemicals, which would be a better reflection of the current situation, have shown conflicting results on the endpoints investigated. Variations in the effects of TH-EDCs on fetal growth have been reported with respect to gender and gestational age. In order to provide better prenatal care and improved health outcomes, it is important that studies be carried out to evaluate the effects of TH-EDCs on lipid levels, insulin sensitivity, and glucose tolerance as they are significant underlying factors in the development of metabolic syndrome.

\section{Conflict of Interests}

The authors have no competing financial interests to declare. 


\section{References}

[1] D. Glinoer, "The regulation of thyroid function in pregnancy: pathways of endocrine adaptation from physiology to pathology," Endocrine Reviews, vol. 18, no. 3, pp. 404-433, 1997.

[2] R. Calvo, M. J. Obregon, C. Ruiz de Ona, F. Escobar del Rey, and G. Morreale de Escobar, "Congenital hypothyroidism, as studied in rats. Crucial role of maternal thyroxine but not of $3,5,3^{\prime}$-triiodothyronine in the protection of the fetal brain," The Journal of Clinical Investigation, vol. 86, no. 3, pp. 889-899, 1990.

[3] L. Préau, J. B. Fini, G. Morvan-Dubois, and B. Demeneix, "Thyroid hormone signaling during early neurogenesis and its significance as a vulnerable window for endocrine disruption," Biochimica et Biophysica Acta (BBA)_Gene Regulatory Mechanisms, vol. 1849, no. 2, pp. 112-121, 2015.

[4] G. A. F. Godoy, T. I. M. Korevaar, R. P. Peeters et al., "Maternal thyroid hormones during pregnancy, childhood adiposity and cardiovascular risk factors: the Generation R study," Clinical Endocrinology, vol. 81, no. 1, pp. 117-125, 2014.

[5] S. Crunkhorn and M. E. Patti, "Links between thyroid hormone action, oxidative metabolism, and diabetes risk?" Thyroid, vol. 18, no. 2, pp. 227-237, 2008.

[6] J. F. Mission, N. E. Marshall, and A. B. Caughey, "Obesity in pregnancy: a big problem and getting bigger," Obstetrical \& Gynecological Survey, vol. 68, no. 5, pp. 389-399, 2013.

[7] D. Galliano and J. Bellver, "Female obesity: short- and long-term consequences on the offspring," Gynecological Endocrinology, vol. 29, no. 7, pp. 626-631, 2013.

[8] A. Yessoufou and K. Moutairou, "Maternal diabetes in pregnancy: early and long-term outcomes on the offspring and the concept of 'metabolic memory"' Experimental Diabetes Research, vol. 2011, Article ID 218598, 12 pages, 2011.

[9] F. Brucker-Davis, "Effects of environmental synthetic chemicals on thyroid function," Thyroid, vol. 8, no. 9, pp. 827-856, 1998.

[10] "The normal thyroid," in Werner and Ingbar's The Thyroid: A Fundamental and Clinical Text, Ba. Cooper, Ed., pp. 1-138, Lippincott Williams \& Wilkins, Philadelphia, Pa, USA, 10th edition, 2012.

[11] S. J. Richardson, "Cell and molecular biology of transthyretin and thyroid hormones," International Review of Cytology, vol. 258, pp. 137-193, 2007.

[12] U. Schweizer, J. M. Weitzel, and L. Schomburg, “Think globally: act locally. New insights into the local regulation of thyroid hormone availability challenge long accepted dogmas," Molecular and Cellular Endocrinology, vol. 289, no. 1-2, pp. 1-9, 2008.

[13] T. J. Visser, "Role of sulfation in thyroid hormone metabolism," Chemico-Biological Interactions, vol. 92, no. 1-3, pp. 293-303, 1994.

[14] Y. Wu and R. J. Koenig, "Gene regulation by thyroid hormone," Trends in Endocrinology and Metabolism, vol. 11, no. 6, pp. 207211, 2000.

[15] P. J. Davis, J. L. Leonard, and F. B. Davis, "Mechanisms of nongenomic actions of thyroid hormone," Frontiers in Neuroendocrinology, vol. 29, no. 2, pp. 211-218, 2008.

[16] M. Boas, U. Feldt-Rasmussen, N. E. Skakkebaek, and K. M. Main, "Environmental chemicals and thyroid function," European Journal of Endocrinology/European Federation of Endocrine Societies, vol. 154, no. 5, pp. 599-611, 2006.

[17] M. J. Silva, J. A. Reidy, A. R. Herbert, J. L. Preau Jr., L. L. Needham, and A. M. Calafat, "Detection of phthalate metabolites in human amniotic fluid," Bulletin of Environmental
Contamination and Toxicology, vol. 72, no. 6, pp. 1226-1231, 2004.

[18] A. M. Calafat, A. R. Slakman, M. J. Silva, A. R. Herbert, and L. L. Needham, "Automated solid phase extraction and quantitative analysis of human milk for 13 phthalate metabolites," Journal of Chromatography B, vol. 805, no. 1, pp. 49-56, 2004.

[19] K. Moriyama, T. Tagami, T. Akamizu et al., "Thyroid hormone action is disrupted by bisphenol A as an antagonist," The Journal of Clinical Endocrinology and Metabolism, vol. 87, no. 11, pp. 5185-5190, 2002.

[20] J. Anselmo, D. Cao, T. Karrison, R. E. Weiss, and S. Refetoff, "Fetal loss associated with excess thyroid hormone exposure," The Journal of The American Medical Association, vol. 292, no. 6, pp. 691-695, 2004.

[21] D. Glinoer, "Miscarriage in women with positive anti-TPO antibodies: is thyroxine the answer?" The Journal of Clinical Endocrinology and Metabolism, vol. 91, no. 7, pp. 2500-2502, 2006.

[22] M. Axelstad, J. Boberg, A. M. Vinggaard, S. Christiansen, and U. Hass, "Triclosan exposure reduces thyroxine levels in pregnant and lactating rat dams and in directly exposed offspring," Food and Chemical Toxicology, vol. 59, pp. 534-540, 2013.

[23] A. Hinther, C. M. Bromba, J. E. Wulff, and C. C. Helbing, "Effects of triclocarban, triclosan, and methyl triclosan on thyroid hormone action and stress in frog and mammalian culture systems," Environmental Science \& Technology, vol. 45, no. 12, pp. 5395-5402, 2011.

[24] P. E. Rodriguez and M. S. Sanchez, "Maternal exposure to triclosan impairs thyroid homeostasis and female pubertal development in Wistar rat offspring," Journal of Toxicology and Environmental Health Part: A, vol. 73, no. 24, pp. 1678-1688, 2010.

[25] P. D. Noyes, S. C. Lema, L. J. Macaulay, N. K. Douglas, and H. M. Stapleton, "Low level exposure to the flame retardant BDE-209 reduces thyroid hormone levels and disrupts thyroid signaling in fathead minnows," Environmental Science and Technology, vol. 47, no. 17, pp. 10012-10021, 2013.

[26] C. M. Butt and H. M. Stapleton, "Inhibition of thyroid hormone sulfotransferase activity by brominated flame retardants and halogenated phenolics," Chemical Research in Toxicology, vol. 26, no. 11, pp. 1692-1702, 2013.

[27] H. M. Stapleton, S. Eagle, R. Anthopolos, A. Wolkin, and M. L. Miranda, "Associations between polybrominated diphenyl ether (PBDE) flame retardants, phenolic metabolites, and thyroid hormones during pregnancy," Environmental Health Perspectives, vol. 119, no. 10, pp. 1454-1459, 2011.

[28] M. Viluksela, A. Raasmaja, M. Lebofsky, B. U. Stahl, and K. K. Rozman, "Tissue-specific effects of 2,3,7,8-tetrachlorodibenzop-dioxin (TCDD) on the activity of $5^{\prime}$-deiodinases I and II in rats," Toxicology Letters, vol. 147, no. 2, pp. 133-142, 2004.

[29] N. Nishimura, Y. Miyabara, M. Sato, J. Yonemoto, and C. Tohyama, "Immunohistochemical localization of thyroid stimulating hormone induced by a low oral dose of 2,3,7,8tetrachlorodibenzo-p-dioxin in female Sprague-Dawley rats," Toxicology, vol. 171, no. 2-3, pp. 73-82, 2002.

[30] J. Chevrier, B. Eskenazi, N. Holland, A. Bradman, and D. B. Barr, "Effects of exposure to polychlorinated biphenyls and organochlorine pesticides on thyroid function during pregnancy," American Journal of Epidemiology, vol. 168, no. 3, pp. 298-310, 2008.

[31] S. Kitamura, N. Jinno, T. Suzuki, K. Sugihara, S. Ohta, H. Kuroki et al., "Thyroid hormone-like and estrogenic activity of 
hydroxylated PCBs in cell culture," Toxicology, vol. 208, no. 3, pp. 377-387, 2005.

[32] H. E. Purkey, S. K. Palaninathan, K. C. Kent, C. Smith, S. H. Safe, J. C. Sacchettini et al., "Hydroxylated polychlorinated biphenyls selectively bind transthyretin in blood and inhibit amyloidogenesis: rationalizing rodent PCB toxicity," Chemistry \& Biology, vol. 11, no. 12, pp. 1719-1728, 2004.

[33] M. Tonacchera, A. Pinchera, A. Dimida et al., "Relative potencies and additivity of perchlorate, thiocyanate, nitrate, and iodide on the inhibition of radioactive iodide uptake by the human sodium iodide symporter," Thyroid, vol. 14, no. 12, pp. 1012-1019, 2004.

[34] P. K. Dasgupta, P. K. Martinelango, W. A. Jackson, T. A. Anderson, K. Tian, R. W. Tock et al., "The origin of naturally occurring perchlorate: the role of atmospheric processes," Environmental Science \& Technology, vol. 39, no. 6, pp. 1569-1575, 2005.

[35] E. N. Pearce, A. M. Leung, B. C. Blount, H. R. Bazrafshan, X. He, S. Pino et al., "Breast milk iodine and perchlorate concentrations in lactating Boston-area women," The Journal of Clinical Endocrinology and Metabolism, vol. 92, no. 5, pp. 16731677, 2007.

[36] C. Schmutzler, I. Hamann, P. J. Hofmann et al., "Endocrine active compounds affect thyrotropin and thyroid hormone levels in serum as well as endpoints of thyroid hormone action in liver, heart and kidney," Toxicology, vol. 205, no. 1-2, pp. 95102, 2004.

[37] C. Schmutzler, A. Bacinski, I. Gotthardt et al., "The ultraviolet filter benzophenone 2 interferes with the thyroid hormone axis in rats and is a potent in vitro inhibitor of human recombinant thyroid peroxidase," Endocrinology, vol. 148, no. 6, pp. 28352844, 2007.

[38] G. R. Wilson and R. W. Curry Jr., "Subclinical thyroid disease," American Family Physician, vol. 72, no. 8, pp. 1517-1524, 2005.

[39] R. M. Gilbert, N. C. Hadlow, J. P. Walsh et al., "Assessment of thyroid function during pregnancy: first-trimester (weeks 9-13) reference intervals derived from Western Australian women," The Medical Journal of Australia, vol. 189, no. 5, pp. 250-253, 2008.

[40] F. Pekonen, H. Alfthan, U.-H. Stenman, and O. Ylikorkala, "Human chorionic gonadotropin (hCG) and thyroid function in early human pregnancy: circadian variation and evidence for intrinsic thyrotropic activity of hCG," The Journal of Clinical Endocrinology and Metabolism, vol. 66, no. 4, pp. 853-856, 1988.

[41] D. Glinoer, "What happens to the normal thyroid during pregnancy?" Thyroid, vol. 9, no. 7, pp. 631-635, 1999.

[42] M. J. Obregon, R. M. Calvo, F. E. Del Rey, and G. M. De Escobar, "Ontogenesis of thyroid function and interactions with maternal function," Endocrine Development, vol. 10, pp. 86-98, 2007.

[43] R. M. Calvo, E. Jauniaux, B. Gulbis et al., "Fetal tissues are exposed to biologically relevant free thyroxine concentrations during early phases of development," Journal of Clinical Endocrinology and Metabolism, vol. 87, no. 4, pp. 1768-1777, 2002.

[44] K. Richard, R. Hume, E. Kaptein et al., "Ontogeny of iodothyronine deiodinases in human liver," The Journal of Clinical Endocrinology and Metabolism, vol. 83, no. 8, pp. 2868-2874, 1998.

[45] J. M. Koopdonk-kool, J. J. M. de Vijlder, G. J. M. Veenboer et al., "Type II and type III deiodinase activity in human placenta as a function of gestational age," Journal of Clinical Endocrinology and Metabolism, vol. 81, no. 6, pp. 2154-2158, 1996.
[46] B. McKinnon, H. Li, K. Richard, and R. Mortimer, "Synthesis of thyroid hormone binding proteins transthyretin and albumin by human trophoblast," Journal of Clinical Endocrinology and Metabolism, vol. 90, no. 12, pp. 6714-6720, 2005.

[47] P. M. Catalano, M. Hoegh, J. Minium et al., "Adiponectin in human pregnancy: implications for regulation of glucose and lipid metabolism," Diabetologia, vol. 49, no. 7, pp. 1677-1685, 2006.

[48] K. A. McLachlan, D. O’Neal, A. Jenkins, and F. P. Alford, "Do adiponectin, TNFalpha, leptin and CRP relate to insulin resistance in pregnancy? Studies in women with and without gestational diabetes, during and after pregnancy," Diabetes/Metabolism Research and Reviews, vol. 22, no. 2, pp. 131138, 2006.

[49] P. M. Catalano, E. D. Tyzbir, R. R. Wolfe, N. M. Roman, S. B. Amini, and E. A. H. Sims, "Longitudinal changes in basal hepatic glucose production and suppression during insulin infusion in normal pregnant women," American Journal of Obstetrics and Gynecology, vol. 167, no. 4, part 1, pp. 913-919, 1992.

[50] N. F. Butte, "Carbohydrate and lipid metabolism in pregnancy: normal compared with gestational diabetes mellitus," The American Journal of Clinical Nutrition, vol. 71, no. 5, supplement, pp. 1256S-1261S, 2000.

[51] E. A. Ryan, "Diagnosing gestational diabetes," Diabetologia, vol. 54, no. 3, pp. 480-486, 2011.

[52] M. Wójcik, M. Chmielewska-Kassassir, K. Grzywnowicz, L. Woźniak, and K. Cypryk, "The relationship between adipose tissue-derived hormones and gestational diabetes mellitus (GDM)," Endokrynologia Polska, vol. 65, no. 2, pp. 134-142, 2014.

[53] K. I. Pappa, M. Gazouli, K. Economou et al., "Gestational diabetes mellitus shares polymorphisms of genes associated with insulin resistance and type 2 diabetes in the Greek population," Gynecological Endocrinology, vol. 27, no. 4, pp. 267272, 2011.

[54] S. J. Chon, S. Y. Kim, N. R. Cho, D. L. Min, Y. J. Hwang, and M. Mamura, "Association of variants in PPAR $\gamma^{2}$, IGF2BP2, and KCNQ1 with a susceptibility to gestational diabetes mellitus in a Korean population," Yonsei Medical Journal, vol. 54, no. 2, pp. 352-357, 2013.

[55] E. A. McAninch and A. C. Bianco, "Thyroid hormone signaling in energy homeostasis and energy metabolism," Annals of the New York Academy of Sciences, vol. 1311, no. 1, pp. 77-87, 2014.

[56] J. Bassols, A. Prats-Puig, P. Soriano-Rodríguez et al., "Lower free thyroxin associates with a less favorable metabolic phenotype in healthy pregnant women," The Journal of Clinical Endocrinology \& Metabolism, vol. 96, no. 12, pp. 3717-3723, 2011.

[57] P. Berbel, J. L. Mestre, A. Santamaría et al., "Delayed neurobehavioral development in children born to pregnant women with mild hypothyroxinemia during the first month of gestation: the importance of early iodine supplementation," Thyroid, vol. 19, no. 5, pp. 511-519, 2009.

[58] P. Cavallo-Perin, A. Bruno, L. Boine, M. Cassader, G. Lenti, and G. Pagano, "Insulin resistance in Graves' disease: a quantitative in-vivo evaluation," European Journal of Clinical Investigation, vol. 18, no. 6, pp. 607-613, 1988.

[59] G. Brenta, "Why can insulin resistance be a natural consequence of thyroid dysfunction?" Journal of Thyroid Research, vol. 2011, Article ID 152850, 9 pages, 2011.

[60] A. Stagnaro-Green, M. Abalovich, E. Alexander et al., "Guidelines of the American Thyroid Association for the diagnosis 
and management of thyroid disease during pregnancy and postpartum," Thyroid, vol. 21, no. 10, pp. 1081-1125, 2011.

[61] G. León, M. Murcia, M. Rebagliato et al., "Maternal thyroid dysfunction during gestation, preterm delivery, and birthweight. The infancia y medio ambiente cohort, Spain," Paediatric and Perinatal Epidemiology, vol. 29, no. 2, pp. 113-122, 2015.

[62] A. Handisurya, G. Pacini, A. Tura, A. Gessl, and A. KautzkyWiller, "Effects of T4 replacement therapy on glucose metabolism in subjects with subclinical $(\mathrm{SH})$ and overt hypothyroidism (OH)," Clinical Endocrinology, vol. 69, no. 6, pp. 963-969, 2008.

[63] M. R. Pickard, A. K. Sinha, L. M. Ogilvie, A. J. Leonard, P. R. Edwards, and R. P. Ekins, "Maternal hypothyroxinemia influences glucose transporter expression in fetal brain and placenta," The Journal of Endocrinology, vol. 163, no. 3, pp. 385394, 1999.

[64] E. Herrera, "Metabolic adaptations in pregnancy and their implications for the availability of substrates to the fetus," European Journal of Clinical Nutrition, vol. 54, supplement 1, pp. S47-S51, 2000.

[65] E. Herrera, "Lipid metabolism in pregnancy and its consequences in the fetus and newborn," Endocrine, vol. 19, no. 1, pp. 43-55, 2002.

[66] H. L. Barrett, M. D. Nitert, H. D. McIntyre, and L. K. Callaway, "Normalizing metabolism in diabetic pregnancy: is it time to target lipids?” Diabetes Care, vol. 37, no. 5, pp. 1484-1493, 2014.

[67] R. Khan, K. Ali, Z. Khan, and T. Ahmad, "Lipid profile and glycosylated hemoglobin status of gestational diabetic patients and healthy pregnant women," Indian Journal of Medical Sciences, vol. 66, no. 7-8, pp. 149-154, 2012.

[68] X. Zhu and S. Y. Cheng, "New insights into regulation of lipid metabolism by thyroid hormone," Current Opinion in Endocrinology, Diabetes \& Obesity, vol. 17, no. 5, pp. 408-413, 2010.

[69] D. Lopez, J. F. Abisambra Socarrás, M. Bedi, and G. C. Ness, "Activation of the hepatic LDL receptor promoter by thyroid hormone," Biochimica et Biophysica Acta, vol. 1771, no. 9, pp. 1216-1225, 2007.

[70] I. J. Goldberg, L.-S. Huang, L. A. Huggins et al., “Thyroid hormone reduces cholesterol via a non-LDL receptor-mediated pathway," Endocrinology, vol. 153, no. 11, pp. 5143-5149, 2012.

[71] C. Pramfalk, M. Pedrelli, and P. Parini, "Role of thyroid receptor $\beta$ in lipid metabolism," Biochimica et Biophysica ActaMolecular Basis of Disease, vol. 1812, no. 8, pp. 929-937, 2011.

[72] Sa. Ibrahem and S. A. Ahmed, "Study of association between lipid profile and thyroid hormones in pregnancy," Journal of AlNahrain University-Science, vol. 16, no. 4, pp. 37-45, 2013.

[73] L. H. Duntas and G. Brenta, "The effect of thyroid disorders on lipid levels and metabolism," The Medical Clinics of North America, vol. 96, no. 2, pp. 269-281, 2012.

[74] M. B. Hapon, S. M. Varas, G. A. Jahn, and M. S. Giménez, "Effects of hypothyroidism on mammary and liver lipid metabolism in virgin and late-pregnant rats," Journal of Lipid Research, vol. 46, no. 6, pp. 1320-1330, 2005.

[75] G. Magnarelli and N. Guiñazú, "Placental toxicology of pesticides," in Recent Advances in Research on the Human Placenta, D. J. Zheng, Ed., chapter 5, InTech, Rijeka, Croatia, 2012.

[76] J. Annamalai and V. Namasivayam, "Endocrine disrupting chemicals in the atmosphere: their effects on humans and wildlife," Environment International, vol. 76, pp. 78-97, 2015.
[77] I. A. T. M. Meerts, Y. Assink, P. H. Cenijn et al., "Placental transfer of a hydroxylated polychlorinated biphenyl and effects on fetal and maternal thyroid hormone homeostasis in the rat," Toxicological Sciences, vol. 68, no. 2, pp. 361-371, 2002.

[78] T. Hamers, J. H. Kamstra, P. H. Cenijn et al., "In vitro toxicity profiling of ultrapure non-dioxin-like polychlorinated biphenyl congeners and their relative toxic contribution to PCB mixtures in humans," Toxicological Sciences, vol. 121, no. 1, pp. 88-100, 2011.

[79] F. A. Grimm, H.-J. Lehmler, X. He, L. W. Robertson, and M. W. Duffel, "Sulfated metabolites of polychlorinated biphenyls are high-affinity ligands for the thyroid hormone transport protein transthyretin," Environmental Health Perspectives, vol. 121, no. 6, pp. 657-662, 2013.

[80] A. C. Gutleb, P. Cenijn, M. V. Velzen et al., "In vitro assay shows that PCB metabolites completely saturate thyroid hormone transport capacity in blood of wild polar bears (Ursus maritimus)," Environmental Science and Technology, vol. 44, no. 8, pp. 3149-3154, 2010.

[81] T. R. Zoeller, "Environmental chemicals targeting thyroid," Hormones, vol. 9, no. 1, pp. 28-40, 2010.

[82] M. M. Tabb and B. Blumberg, "New modes of action for endocrine-disrupting chemicals," Molecular Endocrinology, vol. 20, no. 3, pp. 475-482, 2006.

[83] P. Langer, A. Kočan, M. Tajtáková et al., "Multiple adverse thyroid and metabolic health signs in the population from the area heavily polluted by organochlorine cocktail (PCB, DDE, HCB, dioxin)," Thyroid Research, vol. 2, no. 1, article 3, 2009.

[84] L. Trasande, R. T. Zoeller, U. Hass et al., "Estimating burden and disease costs of exposure to endocrine-disrupting chemicals in the European union," The Journal of Clinical Endocrinology \& Metabolism, vol. 100, no. 4, pp. 1245-1255, 2015.

[85] T. T. Schug, A. M. Blawas, K. Gray, J. J. Heindel, and C. P. Lawler, "lucidating the links between endocrine disruptors and neurodevelopment," Endocrinology, vol. 156, no. 6, pp. 19411951, 2015.

[86] E. Diamanti-Kandarakis, J.-P. Bourguignon, L. C. Giudice et al., "Endocrine-disrupting chemicals: an Endocrine Society scientific statement," Endocrine Reviews, vol. 30, no. 4, pp. 293342, 2009.

[87] M. K. Skinner, M. Manikkam, and C. Guerrero-Bosagna, "Epigenetic transgenerational actions of endocrine disruptors," Reproductive Toxicology, vol. 31, no. 3, pp. 337-343, 2011.

[88] M. de Cock, M. R. de Boer, M. Lamoree, J. Legler, and M. van de Bor, "First year growth in relation to prenatal exposure to endocrine disruptors-a dutch prospective cohort study," International Journal of Environmental Research and Public Health, vol. 11, no. 7, pp. 7001-7021, 2014.

[89] K. Kato, M. J. Silva, L. L. Needham, and A. M. Calafat, "Quantifying phthalate metabolites in human meconium and semen using automated off-line solid-phase extraction coupled with on-line SPE and isotope-dilution high-performance liquid chromatography-tandem mass spectrometry," Analytical Chemistry, vol. 78, no. 18, pp. 6651-6655, 2006.

[90] M. Sun, J. Kingdom, D. Baczyk, S. J. Lye, S. G. Matthews, and W. Gibb, "Expression of the multidrug resistance P-glycoprotein, (ABCB1 glycoprotein) in the human placenta decreases with advancing gestation," Placenta, vol. 27, no. 6-7, pp. 602-609, 2006.

[91] L. M. Aleksunes, Y. Cui, and C. D. Klaassen, "Prominent expression of xenobiotic efflux transporters in mouse extraembryonic 
fetal membranes compared with placenta," Drug Metabolism and Disposition, vol. 36, no. 9, pp. 1960-1970, 2008.

[92] D. L. Shuster, T. K. Bammler, R. P. Beyer et al., "Gestational agedependent changes in gene expression of metabolic enzymes and transporters in pregnant mice," Drug Metabolism \& Disposition, vol. 41, no. 2, pp. 332-342, 2013.

[93] A. C. Collier, M. D. Tingle, J. W. Paxton, M. D. Mitchell, and J. A. Keelan, "Metabolizing enzyme localization and activities in the first trimester human placenta: The effect of maternal and gestational age, smoking and alcohol consumption," Human Reproduction, vol. 17, no. 10, pp. 2564-2572, 2002.

[94] A. C. Collier, N. A. Ganley, M. D. Tingle et al., "UDPglucuronosyltransferase activity, expression and cellular localization in human placenta at term," Biochemical Pharmacology, vol. 63, no. 3, pp. 409-419, 2002.

[95] M. Pasanen, “The expression and regulation of drug metabolism in human placenta," Advanced Drug Delivery Reviews, vol. 38, no. 1, pp. 81-97, 1999.

[96] T. N. Nanovskaya, I. A. Nekhayeva, G. D. V. Hankins, and M. S. Ahmed, "Transfer of methadone across the dually perfused preterm human placental lobule," American Journal of Obstetrics and Gynecology, vol. 198, no. 1, pp. 126.e1-126.e4, 2008.

[97] J. L. Coughlin, P. E. Thomas, and B. Buckley, "Inhibition of genistein glucuronidation by bisphenol A in human and rat liver microsomes," Drug Metabolism and Disposition, vol. 40, no. 3, pp. 481-485, 2012.

[98] B. Balakrishnan, K. Henare, E. B. Thorstensen, A. P. Ponnampalam, and M. D. Mitchell, "Transfer of bisphenol A across the human placenta," American Journal of Obstetrics and Gynecology, vol. 202, no. 4, pp. 393.e1-393.e7, 2010.

[99] B. Balakrishnan, E. B. Thorstensen, A. P. Ponnampalam, and M. D. Mitchell, "Transplacental transfer and biotransformation of genistein in human placenta," Placenta, vol. 31, no. 6, pp. 506$511,2010$.

[100] M. Nishikawa, H. Iwano, R. Yanagisawa, N. Koike, H. Inoue, and H. Yokota, "Placental transfer of conjugated bisphenol A and subsequent reactivation in the rat fetus," Environmental Health Perspectives, vol. 118, no. 9, pp. 1196-1203, 2010.

[101] J. Miyawaki, K. Sakayama, H. Kato, H. Yamamoto, and H. Masuno, "Perinatal and postnatal exposure to bisphenol A increases adipose tissue mass and serum cholesterol level in mice," Journal of Atherosclerosis and Thrombosis, vol. 14, no. 5, pp. 245-252, 2007.

[102] R. Biemann, A. Navarrete Santos, A. Navarrete Santos et al., "Endocrine disrupting chemicals affect the adipogenic differentiation of mesenchymal stem cells in distinct ontogenetic windows," Biochemical and Biophysical Research Communications, vol. 417, no. 2, pp. 747-752, 2012.

[103] R. Biemann, B. Fischer, and A. Navarrete Santos, "Adipogenic effects of a combination of the endocrine-disrupting compounds bisphenol A, diethylhexylphthalate, and tributyltin," Obesity Facts, vol. 7, no. 1, pp. 48-56, 2014.

[104] S. Biswas, J. Buffery, H. Enoch, J. Martin Bland, D. Walters, and M. Markiewicz, "A longitudinal assessment of thyroid hormone concentrations in preterm infants younger than 30 weeks' gestation during the first 2 weeks of life and their relationship to outcome," Pediatrics, vol. 109, no. 2, pp. 222-227, 2002.

[105] J. D. Meeker and K. K. Ferguson, "Relationship between urinary phthalate and bisphenol A concentrations and serum thyroid measures in U.S. adults and adolescents from the National
Health and Nutrition Examination Survey (NHANES) 20072008," Environmental Health Perspectives, vol. 119, no. 10, pp. 1396-1402, 2011.

[106] J. Chevrier, R. B. Gunier, A. Bradman et al., "Maternal urinary bisphenol a during pregnancy and maternal and neonatal thyroid function in the CHAMACOS study," Environmental Health Perspectives, vol. 121, no. 1, pp. 138-144, 2013.

[107] B. Weinberger, A. M. Vetrano, F. E. Archer et al., "Effects of maternal exposure to phthalates and bisphenol A during pregnancy on gestational age," Journal of Maternal-Fetal and Neonatal Medicine, vol. 27, no. 4, pp. 323-327, 2014.

[108] Y. Suzuki, M. Niwa, J. Yoshinaga, Y. Mizumoto, S. Serizawa, and H. Shiraishi, "Prenatal exposure to phthalate esters and PAHs and birth outcomes," Environment International, vol. 36, no. 7, pp. 699-704, 2010.

[109] N. Li, E. Liu, J. Guo et al., "Maternal prepregnancy body mass index and gestational weight gain on offspring overweight in early infancy," PLoS ONE, vol. 8, no. 10, Article ID e77809, 2013.

[110] E. Oken, S. L. Rifas-Shiman, A. E. Field, A. L. Frazier, and M. W. Gillman, "Maternal gestational weight gain and offspring weight in adolescence," Obstetrics \& Gynecology, vol. 112, no. 5, pp. 999-1006, 2008.

[111] D. Dabelea, R. L. Hanson, R. S. Lindsay et al., "Intrauterine exposure to diabetes conveys risks for type 2 diabetes and obesity: a study of discordant sibships," Diabetes, vol. 49, no. 12 , pp. 2208-2211, 2000.

[112] C. Philippat, M. Mortamais, C. Chevrier et al., "Exposure to phthalates and phenols during pregnancy and offspring size at birth," Environmental Health Perspectives, vol. 120, no. 3, pp. 464-470, 2012.

[113] C. Hao, X. Cheng, H. Xia, and X. Ma, “The endocrine disruptor mono-(2-ethylhexyl) phthalate promotes adipocyte differentiation and induces obesity in mice," Bioscience Reports, vol. 32, no. 6, pp. 619-629, 2012.

[114] L. N. Vandenberg, T. B. Colborn, T. B. Hayes et al., "Hormones and endocrine-disrupting chemicals: low-dose effects and nonmonotonic dose responses," Endocrine Reviews, vol. 33, no. 3, pp. 378-455, 2012.

[115] J. D. Meeker, A. M. Calafat, and R. Hauser, "Urinary metabolites of di(2-ethylhexyl) phthalate are associated with decreased steroid hormone levels in adult men," Journal of Andrology, vol. 30, no. 3, pp. 287-297, 2009.

[116] J. C. Lovejoy and A. Sainsbury, "Sex differences in obesity and the regulation of energy homeostasis," Obesity Reviews, vol. 10, no. 2, pp. 154-167, 2009.

[117] T. M. Barber, M. I. McCarthy, J. A. H. Wass, and S. Franks, "Obesity and polycystic ovary syndrome," Clinical Endocrinology, vol. 65, no. 2, pp. 137-145, 2006.

[118] D. Bonofiglio, S. Gabriele, S. Aquila et al., "Estrogen receptor alpha binds to peroxisome proliferator-activated receptor response element and negatively interferes with peroxisome proliferator-activated receptor gamma signaling in breast cancer cells," Clinical Cancer Research, vol. 11, no. 17, pp. 6139-6147, 2005.

[119] C. H. Hurst and D. J. Waxman, "Activation of PPAR $\alpha$ and PPAR $\gamma$ by environmental phthalate monoesters," Toxicological Sciences, vol. 74, no. 2, pp. 297-308, 2003.

[120] M. M. Leijs, L. M. van der Linden, J. G. Koppe et al., "The influence of perinatal and current dioxin and PCB exposure on puberty: a review," Biomonitoring, vol. 1, no. 1, 2014. 
[121] J. L. Tang-Péronard, B. L. Heitmann, H. R. Andersen et al., "Association between prenatal polychlorinated biphenyl exposure and obesity development at ages 5 and $7 \mathrm{y}$ : a prospective cohort study of 656 children from the Faroe Islands," The American Journal of Clinical Nutrition, vol. 99, no. 1, pp. 5-13, 2014.

[122] M. A. Mendez, R. Garcia-Esteban, M. Guxens et al., "Prenatal organochlorine compound exposure, rapid weight gain, and overweight in infancy," Environmental Health Perspectives, vol. 119, no. 2, pp. 272-278, 2011.

[123] K. Konishi, S. Sasaki, S. Kato et al., "Prenatal exposure to PCDDs/PCDFs and dioxin-like PCBs in relation to birth weight," Environmental Research, vol. 109, no. 7, pp. 906-913, 2009.

[124] E. Papadopoulou, I. H. Caspersen, H. E. Kvalem et al., "Maternal dietary intake of dioxins and polychlorinated biphenyls and birth size in the Norwegian Mother and Child Cohort study (MoBa)," Environment International, vol. 60, pp. 209-216, 2013.

[125] E. Vizcaino, J. O. Grimalt, B. Glomstad, A. Fernández-Somoano, and A. Tardón, "Gestational weight gain and exposure of newborns to persistent organic pollutants," Environmental Health Perspectives, vol. 122, no. 8, pp. 873-879, 2014.

[126] K. G. Harley, J. Chevrier, R. Aguilar Schall, A. Sjödin, A. Bradman, and B. Eskenazi, "Association of prenatal exposure to polybrominated diphenyl ethers and infant birth weight," American Journal of Epidemiology, vol. 174, no. 8, pp. 885-892, 2011.

[127] J. Tan, A. Loganath, Y. S. Chong, and J. P. Obbard, "Exposure to persistent organic pollutants in utero and related maternal characteristics on birth outcomes: a multivariate data analysis approach," Chemosphere, vol. 74, no. 3, pp. 428-433, 2009.

[128] M. Vafeiadi, M. Vrijheid, E. Fthenou et al., "Persistent organic pollutants exposure during pregnancy, maternal gestational weight gain, and birth outcomes in the mother-child cohort in Crete, Greece (RHEA study)," Environment International, vol. 64, pp. 116-123, 2014.

[129] M. Vafeiadi, V. Georgiou, G. Chalkiadaki et al., "Association of prenatal exposure to persistent organic pollutants with obesity and cardiometabolic traits in early childhood: the Rhea mother-child cohort (Crete, Greece)," Environmental Health Perspectives, vol. 123, no. 10, 2015.

[130] S. Lignell, M. Aune, P. O. Darnerud, A. Hanberg, S. C. Larsson, and A. Glynn, "Prenatal exposure to polychlorinated biphenyls (PCBs) and polybrominated diphenyl ethers (PBDEs) may influence birth weight among infants in a Swedish cohort with background exposure: a cross-sectional study," Environmental Health, vol. 12, article 44, 2013.

[131] K. L. Kezios, X. Liu, P. M. Cirillio et al., "Prenatal polychlorinated biphenyl exposure is associated with decreased gestational length but not birth weight: archived samples from the Child Health and Development Studies pregnancy cohort," Environmental Health, vol. 11, no. 1, article 49, 2012.

[132] D. Valvi, M. A. Mendez, R. Garcia-Esteban et al., "Prenatal exposure to persistent organic pollutants and rapid weight gain and overweight in infancy," Obesity, vol. 22, no. 2, pp. 488-496, 2014. 


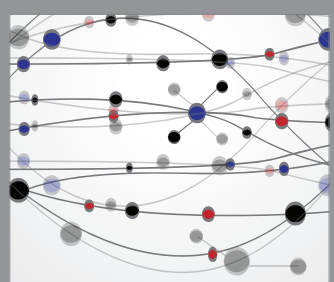

The Scientific World Journal
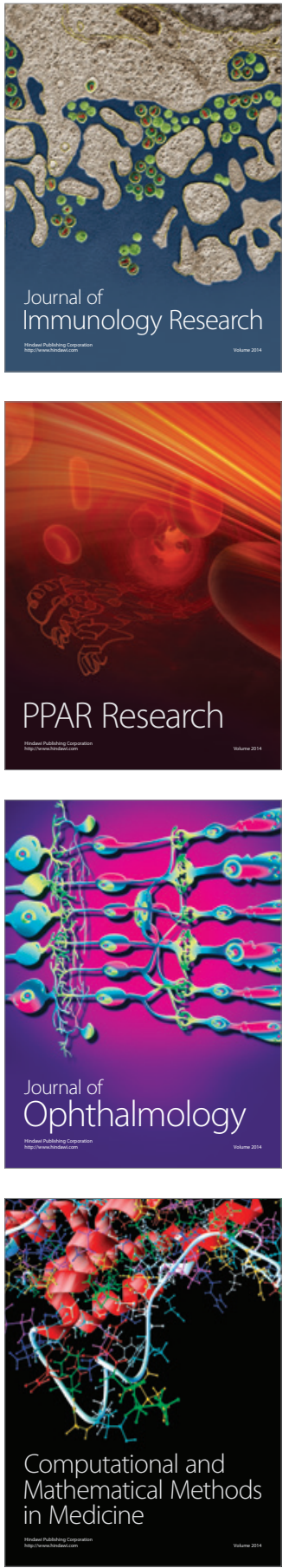

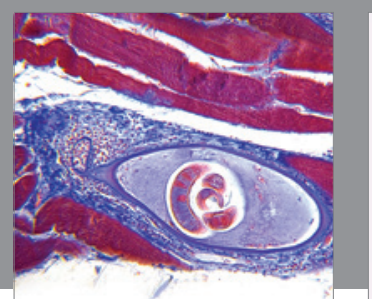

Gastroenterology Research and Practice

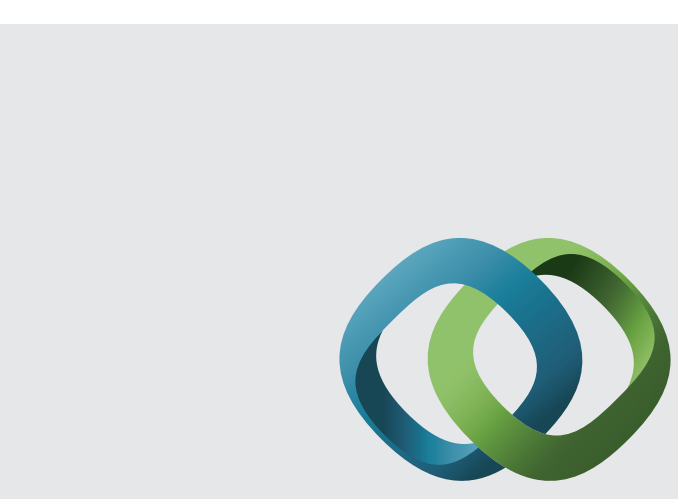

\section{Hindawi}

Submit your manuscripts at

http://www.hindawi.com
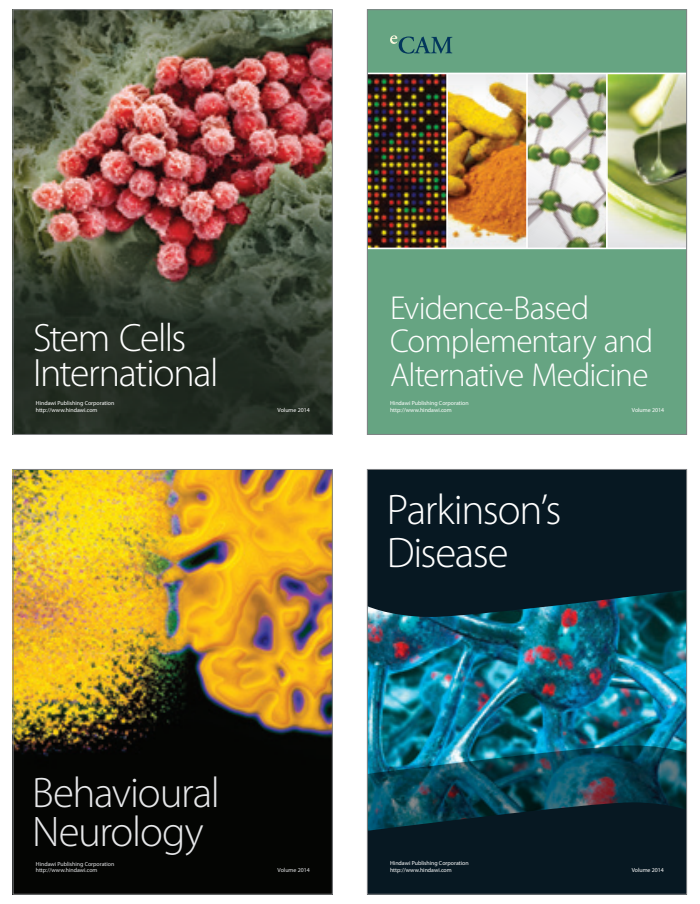
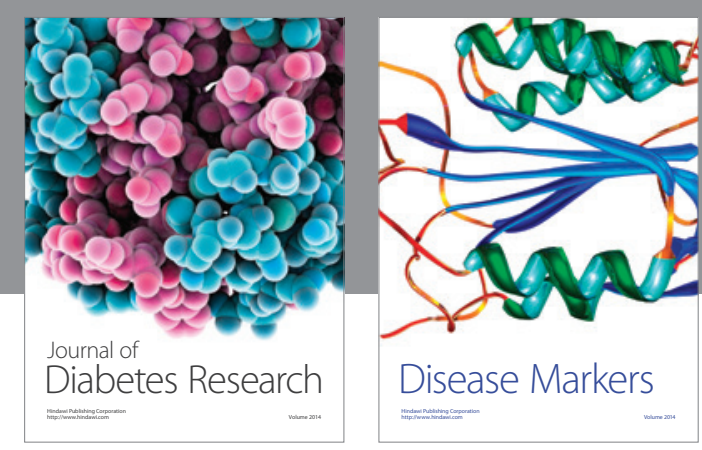

Disease Markers
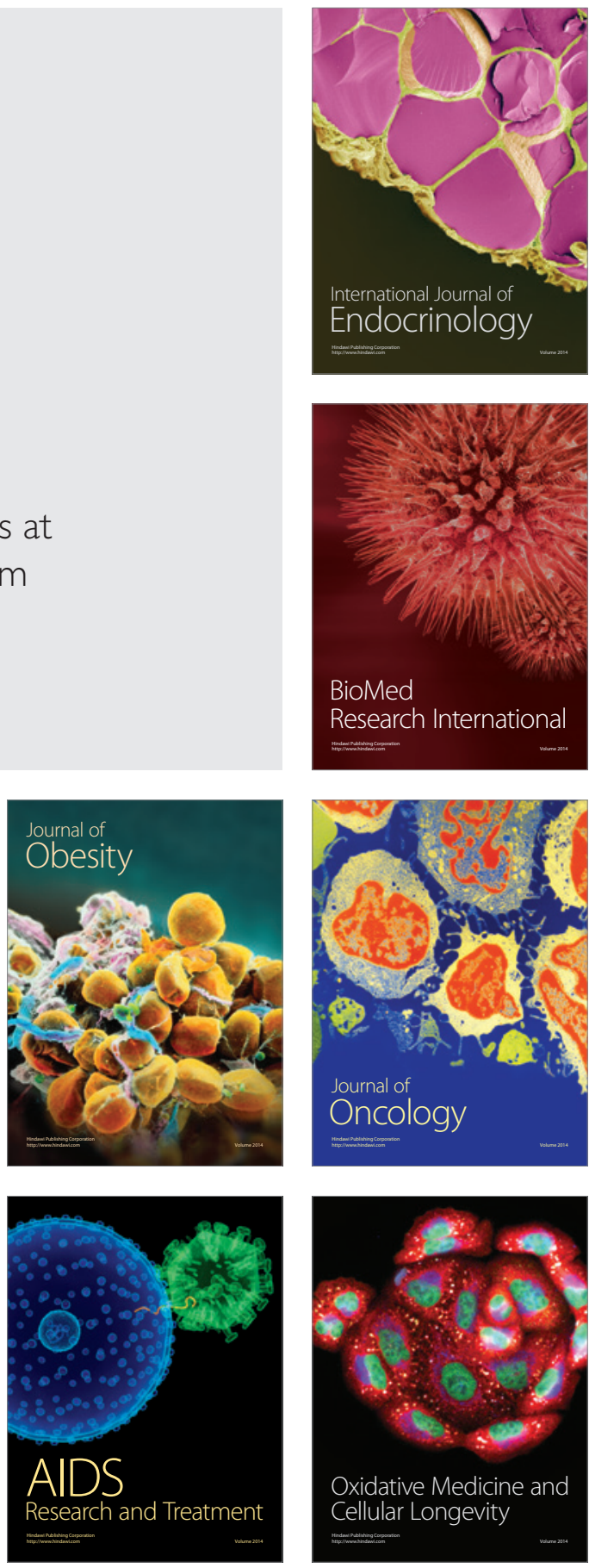